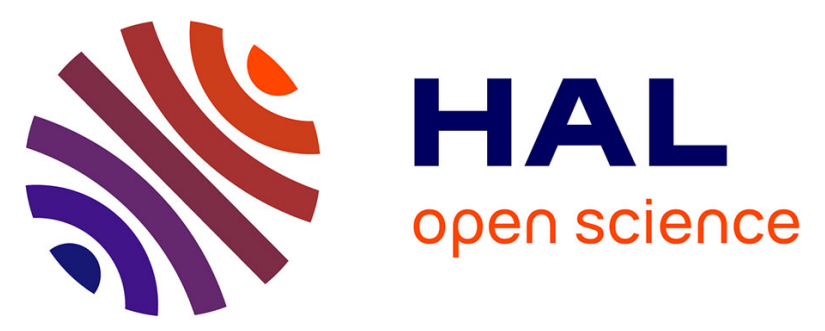

\title{
Analysis of the medical response to November 2015 Paris terrorist attacks: resource utilization according to the cause of injury
}

\author{
Mathieu Raux, Pierre Carli, Frédéric Lapostolle, Matthieu Langlois, Youri
}

Yordanov, Anne-Laure Feral-Pierssens, Alexandre Woloch, Carl Ogereau,

Etienne Gayat, Arié Attias, et al.

\section{To cite this version:}

Mathieu Raux, Pierre Carli, Frédéric Lapostolle, Matthieu Langlois, Youri Yordanov, et al.. Analysis of the medical response to November 2015 Paris terrorist attacks: resource utilization according to the cause of injury. Intensive Care Medicine, 2019, 45 (9), pp.1231-1240. 10.1007/s00134-019-05724-9 . hal-02292176

\section{HAL Id: hal-02292176 \\ https://hal.sorbonne-universite.fr/hal-02292176}

Submitted on 19 Sep 2019

HAL is a multi-disciplinary open access archive for the deposit and dissemination of scientific research documents, whether they are published or not. The documents may come from teaching and research institutions in France or abroad, or from public or private research centers.
L'archive ouverte pluridisciplinaire HAL, est destinée au dépôt et à la diffusion de documents scientifiques de niveau recherche, publiés ou non, émanant des établissements d'enseignement et de recherche français ou étrangers, des laboratoires publics ou privés. 


\title{
Analysis of the medical response to November2015 Paris terrorist attacks: resource utilization according to the cause of injury
}

\author{
Mathieu Raux, ${ }^{1,2}$ Pierre Carli, ${ }^{3,4}$ Frédéric Lapostolle, ${ }^{5,6}$ Matthieu Langlois, ${ }^{7}$ \\ Youri Yordanov, ${ }^{1,8}$ Anne-Laure Féral-Pierssens, ${ }^{9}$ Alexandre Woloch, ${ }^{10}$ \\ Carl Ogereau, ${ }^{11}$ Etienne Gayat, ${ }^{12,13}$ Arié Attias, ${ }^{14}$ Dominique Pateron, ${ }^{1,8}$ Yves
} Castier, ${ }^{13,15}$ Anne François, ${ }^{16}$ Bertrand Ludes, ${ }^{4,17}$ Emmanuelle Dolla, ${ }^{2}$ Jean-Pierre Tourtier, ${ }^{18}$ and Bruno Riou, ${ }^{1,19}$ for the TRAUMABASE Group.

Authors details:

${ }^{1}$ Sorbonne Université, UMRS Inserm 1158,UMRS Inserm 1166, IHU ICAN, and UMRS Inserm 1136, Paris France; ${ }^{2}$ Assistance Publique-Hôpitaux de Paris (APHP), Hôpital Pitié-Salpêtrière, Department of Anaesthesiology and Critical Care, Paris; ${ }^{3}$ APHP, SAMU 75, Hôpital Necker-Enfants Malades, Paris; ${ }^{4}$ UniversitéParis Descartes, Paris; ${ }^{5}$ APHP, SAMU 93, Hôpital Avicenne,Bobigny; ${ }^{6}$ Université Paris 13, Bobigny; ${ }^{7}$ Service Médical du RAID, Bièvres; ${ }^{8}$ APHP, Hôpital Saint-Antoine, Department of Emergency, Paris; ${ }^{9}$ APHP, Hôpital Européen Georges Pompidou, Emergency Department, Paris; ${ }^{10}$ Hôpital d'Instruction des armées (HIA) Begin, Department of Emergency, Saint Mandé, France; ${ }^{11}$ APHP, Hôpital Saint Louis, Department of Emergency, Paris ; ${ }^{12}$ APHP,Hôpital Lariboisière, Department of Anesthesiology and Critical Care, Paris ; ${ }^{13}$ Université Paris Diderot, Paris; ${ }^{14}$ APHP, Hôpital Henri Mondor, Department of Anaesthesiology and Critical Care, Créteil, France; ${ }^{15}$ APHP, Hôpital Bichat, Division of vascular surgery, Paris; ${ }^{16}$ Etablissement Français du Sang, Paris; ${ }^{17}$ Institut Médico-légal de Paris, Paris; ${ }^{18}$ Brigade de Sapeurs-Pompiers de Paris, Paris; ${ }^{19} \mathrm{APHP}$, Hôpital Pitié-Salpêtrière, Department of emergency medicine and surgery, Paris; all in France.

\section{ORCID reference:}

Pr. Mathieu RAUX: 0000-0003-2493-9146

Word count: 3.498

38 references

3 figures +1 table

1 supplementary material (Online Resource 1)

\section{Corresponding author:}

Pr. Mathieu RAUX, Département d’Anesthésie Réanimation et Médecine Périopératoire Groupe Hospitalier Pitié-Salpêtrière, Assistance Publique-Hôpitaux de Paris, 47-83 boulevard de l’Hôpital, 75651 Paris CEDEX 13 France.

Téléphone : +33-1-42-17-72-04

Fax : +33-1-42-17-73-88

mathieu.raux@aphp.fr 


\begin{abstract}
(244 words)
Purpose: The majority of terrorist acts are carried out by explosion or shooting. The objective of this study was first, to describe the management implemented to treat a large number of casualties and their flow together with the injuries observed, and second, to compare these resources according to the mechanism of trauma.

Methods: This retrospective cohort study collected medical data from all casualties of the attacks on November $13^{\text {th }} 2015$ in Paris, France, with physical injuries, who arrived alive at any hospital within the first 24 hours after the events. Casualties were divided into two groups: explosion injuries and gunshot wounds.
\end{abstract}

Results: 337 casualties were admitted to hospital, 286 (85\%) from gunshot wounds and 51 (15\%) from explosions. Gunshot casualties had more severe injuries and required more inhospital resources than explosion casualties. Emergency surgery was required in 181 (54\%) casualties and was more frequent for gunshot wounds than explosions injuries (57\% vs. 35\%, $p<0 \cdot 01)$. The types of main surgery needed and their delay following hospital admission were as follows: orthopaedic ( $\mathrm{n}=107$ (57\%); median $744 \mathrm{~min})$; general ( $\mathrm{n}=27$ (15\%); $90 \mathrm{~min})$; vascular (n=19 (10\%); median $53 \mathrm{~min})$, thoracic ( $\mathrm{n}=19(10 \%) ; 646 \mathrm{~min})$, and neurosurgery ( $\mathrm{n}=4$ (2\%); $198 \mathrm{~min})$.

Conclusion: The resources required to deal with a terrorist attack vary according to the mechanism of trauma. Our study provides a template to estimate the proportion of various types of surgical resources needed overall, as well as their time-frame in a terrorist multisite and multi - type attack.

Key words: Terrorism; Disaster medicine; Mass casualty; Bombing; Gunshot wound; Emergency Surgery.

Funding : Assistance Publique-Hôpitaux de Paris. 
Take home message (46 words)

Analysis of the terrorist attacks of November the $13^{\text {th }} 2015$ in Paris, showed that gunshot casualties were more seriously injured and required greater resources than explosion injuries casualties. This analysis enables the modification of future management plans, particularly for possibly scarce resources such as specialist surgery.

\section{0-character Tweet (138 characters)}

During 2015 Paris attack, gunshot casualties were more seriously injured and required greater resources than explosion injuries casualties 


\section{Introduction}

Europe has recently been the target of many terrorist attacks using explosives, war weapons, and trucks $[1,2]$. These have resulted in mass casualty events (MCE). Continuing conflicts worldwide indicate that European countries will face such situations for a long time as terrorism becomes more widespread and increasingly violent. The medical response is an essential component of the response to terrorist attacks since they are designed to kill and injure the largest number of people, using simultaneous attacks and/or multiple means [2]. The conclusions of the publications describing the medical care of casualties from mass shootings over the past 20 years must be interpreted with caution, as their pre-hospital organisations differ from Western European ones [3-6]. Recently, Timbie et al. pointed out that there was a lack of data to manage rare resources in the event of MCE [7].

On November $13^{\text {th }}, 2015$, Paris was the scene of simultaneous multiple terrorist attacks causing casualties which were unprecedented since the Second World War. They used explosives and assault rifles, both on streets, café terraces, and in a theatre [2,8]. Counter terrorism operations of the police and army, together with the presence of active gunmen, and hostage taking, had an impact on the management of casualties, and delayed access to the hospital and the operating theatre.

In the present study, we analyse globally this unique cohort of casualties, characterized by a unity of place and a very large number of casualties in a short period of time, to describe primarily the pre and intra-hospital management implemented to treat the large number of casualties and their flow together with the injuries observed. Secondarily, the coexistence of two mechanisms of trauma made it possible to test the hypothesis that the resources needed to treat the injured depend on the injury process (explosion vs. gunshot). We believe the present analysis provides important and relevant information to better adapt our future emergency plans. 


\section{Methods}

This observational retrospective cohort study used medical data from casualties of the Paris area terrorist attacks, collected anonymously. Data processing authorisation was obtained from the Commission Nationale Informatique et Liberté (\#DR-2016-234) and the Comité de Protection des Personnes Île de France, exempting casualties from giving their consent for the use of their data for observational research purposes. This report follows the STROBE recommendations [9]. Some of the data have been published earlier [10-12].

\section{Study population}

Casualties from the attacks of 13 November 2015 included in the study were those with body injuries and who arrived alive at the hospital before 14 November 2015 11:59 pm. Casualties without body injuries, those consulting for psychological trauma, or those presenting to hospital later after the events were excluded. Casualties whose medical records were empty and who were not hospitalized were considered free of somatic lesions and were therefore not included.

\section{Exposure to mechanism of trauma and management}

On 13 November 2015, three terrorists triggered their explosive vests near a football stadium, at 9:20pm. At the same time, a few kilometres away, other terrorists opened fire on customers sitting at the terrace of three restaurants with military weapons (Kalashnikov model AK-47, calibre $7 \cdot 62 \mathrm{~mm}$ ). One of them triggered his explosive vest in a fourth restaurant. Three terrorists started shooting the spectators of a concert hall at 9:49pm and took the survivors hostage. It took three hours for the Police and French Special Weapons and Tactics (SWAT) to neutralize terrorists. During this delay, the extraction and care of the surviving casualties was organized by the medical officers of the SWAT [13]. Casualties were then managed and 
transported to hospitals by medicalised mobile intensive care units and/or by Fire-Brigade EMT - manned ambulances according to the French standards of prehospital care [14]. Hospital orientation was managed by the Service Aide Médicale Urgente (SAMU), a medicalised civil emergency medical service [14]. The qualitative analysis of events by each stakeholder has been already published [10-12,15]. When needed, priority was given to secure the premises before access to casualties and their evacuation to hospitals in the Paris region, six of them being level-1 trauma $[8,16]$.

\section{Measurement and analysis}

Casualties were identified by accessing the computer files of the Paris Préfecture de Police (police general staff) and Assistance Publique-Hôpitaux de Paris (Paris public hospitals), of each emergency department in the Île-de-France population basin, and consulting the medical files corresponding to an admission between November 13, 2015 at 9:30pm and November 14, 2015 at 11:59 pm. The links between these exhaustive files were made using the casualty's names in each file. Those names were missing from the anonymous file used for the analysis.

Descriptive data on casualties, sex, wounding process, anatomical injuries, their impact on vital functions (systolic arterial pressure, heart rate, Glasgow coma score, pulse oximetry), pre-hospital categorization (triage) and mean times of transfer to hospital were collected. Casualties were sorted in the pre-hospital setting on the basis of their injuries, their impact on vital functions, the response to the pre-hospital treatment, the need for further treatment and the degree of urgency of the latter. To do this, the sorting used a simplified scale derived from the North Atlantic Treaty Organization (NATO) sorting scale [17]. Any casualty triaged as requiring immediate care according to NATO, regardless of the final anatomical injuries, was categorized as absolute emergency (AE). The remaining casualties were categorized as relative 
emergency (RE) [18]. Information regarding triage were extracted from the "SINUS" and "VICTIMS" files of the Préfecture de Police de Paris and Assistance Publique-Hôpitaux de Paris. When missing, this information was completed considering the destination. Therapeutic measures implemented in the pre-hospital (catecholamine administration, tracheal intubation) and hospital settings (blood transfusion, haemostatic agents, chest tube insertion, surgery, embolization, mechanical ventilation, catecholamine administration, renal replacement therapy, hospitalisation in intensive care unit —ICU—) and hospital diagnostic (laboratory investigation, X-ray examination, ultrasonography, CT-scan) were also recorded, as well as surgery times. Information on casualty progress up to discharge from hospital (length of stay in ICU, in hospital, orientation at hospital discharge) was collected. Data were censored upon discharge from hospital. These variables were entered by the corresponding investigators in each hospital that received casualties, based on the victim's medical file. Because of the purely observational nature of the study, casualties were not reconvened. When investigators were unable to enter these data, two authors (MR, ED) entered the data from the hospitalization and surgical records available. For the sake of completeness, all medical reports were reviewed by these two authors, to complete missing data and to ensure centralized coding of anatomical injuries using the Abbreviated Injury Scale dictionary [19].

The Revised Trauma Score (RTS) scores, Injury Severity Score (ISS), and the Trauma Related Injury Severity Score (TRISS) were calculated [20], using updated coefficients [21]. Where arterial pressure and Glasgow score variables were missing, RTS was estimated by maximizing the probability of survival. Observed mortality was defined as the occurrence of death during hospitalization and compared to expected mortality [21]. Transfer was defined as referring the casualty to a hospital other than the one that initially received the casualty, within 24 hours of the mechanism of trauma. Hospital arrival times were calculated from the assumed injury schedules (see above) and arrival time on the medical record. Access times to the 
operating theatre were calculated on the basis of hospital arrival and operating theatre arrival times, the latter being obtained by examining the operating room records. Casualties were allocated to two groups according to the injury process: explosion vs. gunshot wound. When this information was missing, the injury process was the one mainly observed at the injury site. The characteristics of the most severely wounded casualties (ISS $>15$ ) were described separately.

\section{Statistical analysis}

Qualitative variables are presented by number and percentage. Quantitative variables are presented by their mean \pm standard deviation or median [interquartile range] according to the normality of the distribution. Comparison between groups was performed using the Fisher exact method, the Student t test, and the Mann and Whitney test. Agreement between experts was performed using the Kappa score. Missing data were not replaced. All comparisons were two-tailed and a $p$ value $<0.05$ was considered significant. 


\section{Results}

\section{Study population}

Of the 543 casualties with physical injuries identified, 337 were admitted to emergency services/trauma centres (16 civilian and 2 military hospitals) within 24 hours of the terrorist attacks (Fig. 1).

\section{Pre and intra-hospital management}

Casualties suffered from gunshot wounds $(n=286,85 \%)$ or explosion injuries $(n=51$, 15\%). One hundred and ninety-six casualties (58\%) came from the concert hall, of whom a non-evaluable fraction was held hostage. Only 119 (36\%) casualties benefited from the installation of an identification bracelet during prehospital phase. Two hundred and sixty-two casualties (77\%) were triaged during the prehospital phase. Thirteen (4\%) received orotracheal intubation and 9 (3\%) catecholamine administration. The global cumulative frequency of delays from injury to hospital admission is shown in Figure 2A. Two waves of hospital admissions were identified at 150- and 240-min following injury. Physiological variables, diagnostic and therapeutic strategies are described in table 1. CT-scans were performed only in hemodynamically stable casualties (spontaneously or after resuscitation), meaning the most severe casualties entered the operating room without having a whole-body CT-scan. Emergency surgery was required in 181 (54\%) cases. The global cumulative frequency of delays from hospital admission to operating theatre is shown in Figure 2B. Surgical needs were mainly for orthopaedic surgery (Table 1 and Fig.3A). Haemostasis procedures were immediately performed on hospital arrival for the most severely injured casualties (Fig. 3A and 3B), starting 75 min after injury. These were performed according to the principles of damage control in haemodynamically unstable casualties. Although some orthopaedic operations began within the first hour, they were infrequent in the initial phase (Fig. 3A and 3B). Forty-four extra operating 
rooms on top of 31 available (+ 141\%) were recruited to perform emergency surgery after notification of the MCE and implementation of the public hospital disaster plan. The fate of casualties at the end of the initial phase of care is shown in Table 1 . Of the 97 casualties hospitalized in the ICU, 42 (43\%) were admitted to the hospital in the trauma bay, which is an ICU environment. The remaining 55 (57\%) were transferred to ICU immediately after the OR, with a median [interquartile] delay of 378 [240-909] min after hospital arrival. Twenty-seven casualties (8\%) required transfer to another hospital within the first 24hours, either because the operating theatres were saturated or to benefit from surgical expertise not available in the initial hospital, irrespective of the nature of the mechanism of trauma. Seven casualties died, all from injuries due to shooting, on day one. Overall the observed mortality of the casualties hospitalized alive ( $n=7 ; 2 \cdot 1 \%)$ was not significantly different from that expected $(n=11 ; 3 \cdot 3 \%$; $p=0.92$ ). Those who survived were mainly discharged home (Table 1 ). The most severely affected casualties, defined by an ISS greater than 15, all benefited from management in an ICU. Their characteristics and care are detailed in Online Resource 1.

\section{Effects of the mechanism of injury}

Neither hospital access time nor physiological variables were affected by the mechanism of trauma (Table 1). The severity of the lesions observed by anatomical region was independent of the mechanism of trauma (Table 1). Although the proportion of casualties with ISS $>15$ was the same in both groups, those with gunshot wounds experienced more severe injuries than those who were bombed and had lower probability of survival (Table 1). In hospital, the proportion of casualties with gunshot wounds having laboratory investigations was greater than that of casualties of explosions (Table 1). The proportions of casualties having Xrays, FAST, and whole-body CT-scans were the same between the two groups. Gunshot wound casualties had similar needs of initial resuscitative measures (tranexamic acid administration, 
fibrinogen concentrate administration, chest-tube insertion, mechanical ventilation and catecholamine administration) than casualties from explosion, except for a higher incidence of surgery and blood transfusion (Table 1). Both gunshot and explosion casualties had similar access to the operating room (Fig. 2B). The incidence of first surgical specialty types and delays to initial surgery were the same in both groups, regardless of the specialty, apart from general surgery, which was performed earlier in gunshot wounds casualties than in those wounded by explosion (Fig. 3B). Embolization was more frequent in casualties with gunshot wounds. Apart from blood transfusion, medical management in ICU was not affected by the mechanism of trauma (Table 1). The proportion of casualties discharged home on the same day was greater after explosions than after gunshot but when casualties were admitted, their hospital length of stay was longer (Table 1). Requirement for ICU care was the same in the two groups, but casualties of bombing stayed three-days longer in ICU. 


\section{Discussion}

This study describes the severity of injuries and means implemented to deal with the 337 casualties of a multimodal terrorist act, using explosives and military weapons, that occurred in the urban environment of a major European capital. This study also shows that casualties with high energy ballistic trauma had more severe injuries and required more hospital resources than those suffering from explosion.

The injuries appeared to be less severe than those previously reported [22, 23]. In contrast to the study by Gaarder et al.[23] or Einav et al. [4], all casualties of the Paris attacks were included, whether they were cared for in trauma centers or in local hospitals, and whether they were subsequently hospitalized or not, resulting in lowering the median ISS. The proportion of severely injured casualties (ISS $>15$ ) is similar to that reported by TueragnoFuentes et al. [24]. However, the number of inpatients admitted after the Paris attacks is twice as high as that observed after the Madrid attacks, confirming the greater severity of firearm injuries on that of explosion $[3,24]$.

The dichotomous scale (AE/RE) used was chosen because it corresponded to that taught in France, in line with the recommendations of simplicity provided in the aftermath of the London attacks [25]. Pre-hospital resuscitation procedures were limited to essential measures, in accordance with French recommendations [26, 27]. As previously described in other major multisite terrorist attacks, evacuation times were impacted by the local circumstances [22, 23, 25, 28], but unaffected by the mechanism of trauma. Neither the premises nor the evacuation routes were secure, as some terrorists were at large while others took some victims hostage. This explains why it took more than three hours for half of the casualties to access the hospital [29]. It is noteworthy that part of the victims of the hostage-taking have been treated and their evacuation from the theater prioritized by tactical physicians of the SWAT teams. Consequently, comparison with single-site bombings occurring close to trauma centres seems 
questionable [23, 30, 31]. The decision to time the wounding process at 9:49pm for all theater casualties might have overestimated evacuation delays for those who were held hostage and wounded later. Referral to hospitals seemed appropriate, as the transfer rate was lower than that reported by Leibovici et al. [32].

The similar use of radiological examinations between the two groups should be interpreted with caution, as their time frame was unknown. The impact of the implementation of the FAST was significantly lower than that previously reported in the London bombings [24]. The incidence of CT scans appears to be similar, considering that in the present cohort, these were whole-body CT scans with contrast injection, and not targeted examinations [33]. These CT scans were performed to evaluate the projectile trajectory [34], as well as associated organ and vascular damage [35]. The higher incidence of surgery and transfusion among casualties with gunshot wounds was related to their greater severity, as previously reported [3].

The delays to access operating rooms were similar to those previously reported $[4,25$, 36]. The first procedures performed were haemostatic, a quarter of which were for thoracic or abdominal surgeries, as previously reported [22, 23, 25, 31], without consideration of the mechanism of trauma (Table 1, Fig.3). Immediate access to operating rooms for haemostatic or resuscitative surgery is attributed to the large number of available operation rooms and appropriate distribution of casualties to hospitals. This availability was increased by the SAMU early notification to the hospitals of the terrorist attacks allowing rapid backup of surgical teams. During the evening, hospital orientations were also adapted by sharing information on the casualties surge between the EMS headquarters and the trauma centers. While orthopaedic surgical teams were called upon from the beginning of the influx into the operating room to perform haemostatic procedures on the limbs, or to assist visceral and thoracic surgeons, the bulk of their orthopaedic activity only began once bleeding emergencies had been treated, to ensure the repair of limb injuries. This surgical activity lasted well beyond the first twelve 
hours, encouraging as much as possible to keep surgical human resources available in the long term (Fig.3). Such an approach allows replacement of the first teams involved and availability to face another terrorist attack.

The length of stay in ICU was lower in casualties with gunshot wounds compared with those with explosion injuries, even though the severity of their injuries and therapeutic needs were the same, and lower than previously reported in Europe [22, 23, 25, 31]. Casualties admitted to ICU did not all require extensive ICU care and/or procedures. They rather needed high-dependency unit (HDU) care. This suggest to free up HDU type beds in the case of an even like this. The observed mortality was comparable to the expected mortality, both for the study population or the most severely injured ones (Table 1 and Supplementary material), despite the MCE circumstances. However, it remained lower than the overall mortality of the event (24\%), due to the non-inclusion of deceased casualties at the scene of the killings. We cannot exclude that some pre-hospital deaths would have occurred in hospital if the casualties had been referred earlier, thereby increasing intra-hospital mortality, as observed by Einav et al with shorter prehospital time [4].

The strength of our study is related to the large number of civilian casualties with gunshot wounds, the highest reported to date for a terrorist incident in Europe. Beyond reinforcing the robustness of our results, this number of casualties contributes to explain the recruitment of additional resources (operating rooms, surgical teams), given that case-load in a mass casualty is a function of surge capacity [37]. The inclusion of all casualties enabled focusing on those deemed wrongly less severe (ISS $<15$ ), showing they required significant medical resources, as evidenced by a hospitalization rate twice that of the Madrid attacks [24]. This approach also enables the estimation of the real burden of care required for all surviving casualties. The similarity of a number of results (use of surgery, resuscitation, CT scans) attests to the robustness of this information and its generalizability. Another strength of this study is 
the uniqueness of the location and time of events, together with prehospital medicalization, which contrasts first with the spatial and temporal dispersion of terrorist acts and the scoop and run approach in the prehospital setting $[3,4,28]$. Finally, this study brought new elements. The presentation of the physiological impact of injuries on vital functions made it possible, in addition to characterizing casualties, to estimate expected mortality. It provided descriptive elements of the consumption of diagnostic resources (biological, radiological, ultrasound). Finally, it detailed the therapeutic procedures implemented during the hospitalization of these casualties.

This study has several limitations, suffering from bias inherent to its retrospective nature, in particular the existence of missing data related to the non-standardization of information contained in medical records, either during the pre-hospital or hospital phases. This argues in favour of the dissemination of a template for data collection in disaster medicine for medical and research purposes, allowing data to be pooled and compared, as suggested by Bradt et al. [38]. The descriptive nature of the main objective precluded any calculation of the sample size. The choice to group all hospitals into a single simulated one may also affect the internal validity of the study. However, this is probably the best way to ensure a global analysis that would provide relevant information for future contingency plans.

In conclusion, the analysis of the terrorist attacks in Paris, carried out using explosives and automatic rifles, provides a description of the proportion of various types of surgical resources needed, as well as their time-frame in a terrorist multisite and multi modal attack. It also showed that casualties with gunshot wounds arriving alive at the hospital were more seriously affected and required more resources than the explosion casualties. The mobilization of thoracic and general surgery teams to perform haemostasis surgery were immediate in the event of penetrating trauma. Orthopaedic surgery and ICU teams were not solicited as very first line treatment. They only intervened later. Hospitals receiving injured people were engaged for 
many hours. It was therefore advisable to keep resources (or even hospitals) in reserve in case of a succession of attacks. These quantitative elements might help to adapt future management plans for a mass influx of casualties to the realities on the ground, particularly for scarce resources such as surgery. 
Acknowledgement: We thank Dr. David Baker DM, FRCA, (Emeritus Consultant Anaesthesiologist, Department of Anaesthesiology and Critical Care, Hôpital Necker-Enfants Malades, Paris) for reviewing the manuscript.

Declaration of interest: On behalf of all authors, the corresponding author states that there is no conflict of interest.

Role of the funding source: Assistance Publique-Hôpitaux de Paris provided a grant to pay for data collection. The TraumaBase group was supported only by institutions. Assistance Publique-Hôpitaux de Paris was not involved in analysis, interpretation of the data nor writing the report or decision to submit the paper for publication.

\section{Author contributions:}

MR and BR conceived and designed the study. MR, ED, YY, ALF, AA collected, anonymised, and prepared the data. MR and BR analysed and interpreted the data. MR, PC, JPT and BR wrote the initial draft. All authors subsequently critically edited the report. All authors read and approved the final report. MR had full access to all of the data in the study and take responsibility for the integrity of the data and the accuracy of the data analysis. MR and BR obtained funding and supervised the study. 


\section{References}

1 Carles M, Levraut J, Gonzalez JF, Valli F, Bornard L, et al. (2016) Mass casualty events and health organization: terrorist attack in Nice. Lancet 388:2349-2350

2 Carli P, Pons F, Levraut J, Millet B, Tourtier JP, Ludes B, Lafont A, Riou B (2017) The French emergency medical services after the Paris and Nice terrorist attacks: what have we learnt? Lancet390:2735-2738

3 Peleg K, Aharonson-Daniel L, Stein M, Michaelson M, Kluger Y, Simon D, Noji EK (2004) Gunshot and explosion injuries: characteristics, outcome and implications for care of terror-related injuries in Israel. Ann Surg 239:311-318

4 Einav S, Aharonson-Daniel L, Weissman C, Freund HR, Peleg K (2006) In-hospital resource utilization during multiple casualty incidents. Ann Surg 243:533-540

5 Turner CDA, Lockey DJ, Rehn M (2016) Pre-hospital management of mass casualty civilian shootings: a systematic literature review. Crit Care 20:362.

6 Klassen AB, Marshall M, DaiM, Mann NC, Sztajnkrycer MD (2019) Emergency medical services response to mass shooting and active shooter incidents, United States, 2014-2015. Prehosp Emerg Care 23:159-166

7 Timbie JW, Ringel JS, Fox DS, Pillemer F, Waxman DA, Moore M, Hansen CK, Knebel AR, Ricciardi R, Kellerman AL (2013) Systematic review of strategies to manage and allocate scarce resources during mass casualty events. Ann Emerg Med 61:677-689

8 Hirsch M, Carli P, Nizard R, Riou B, Baroudjian B, Baubet T, Chhor V, Chollet-Xemard C, Dantchev N, Fleury N, Fontaine JP, Yordanov Y, Raphael M, Paugam Burtz C, Lafont A (2015) The medical response to multisite terrorist attacks in Paris. Lancet 386:25352538 
9 von Elm E, Altman DG, Egger M, Pocock SJ, Gøtzsche PC, Vandenbroucke JP (2007) The strengthening the reporting of observational studies in epidemiology (STROBE) statement: guidelines for reporting observational studies. PLoS Med 4:1623-1627

10 Gregory TM, Bihel T, Guigui P, Pierrart J, Bouyer B, Magrino B, Delgrande D, Lafosse T, Al Khaili J, Baldacci A, Lonjon G, Moreau S, Lantieri L, Alsac JM, Dufourcq JB, Mantz J, Juvin P, Halimi P, Douard R, Mir O, Masmejean E (2016) Terrorist attacks in Paris: Surgical trauma experience in a referral center. Injury 47:2122-2126

11 Tresson P, Touma J, Gaudric J, Pellenc Q, Le Roux M, Pierret C, Kobeiter H, Julia P, Goeau-Brissonniere O, Desgranges P, Koskas F, Castier Y (2017) Management of vascular trauma during the Paris terrorist attack of November 13, 2015. Ann Vasc Surg $40: 44-49$

12 Femy F, Follin A, Juvin P, Feral-Pierssens AL (2018) Terrorist attacks in Paris: managing mass casualties in a remote trauma center. Eur J Emerg Med ePub ahead of print.

13 Service Médical du RAID (Recherche, Assistance, Intervention, Dissuasion) (2016) Tactical emergency medicine: lessons from Paris marauding terrorist attack. Crit Care 20:37

14 Adnet F, Lapostolle F (2004) International EMS systems: France. Resuscitation 63:7-9

15 Borel M, Rousseau R, Le Saché F, Pariente D, Castro S, Delay M, Hausfater P, Raux M, Menegaux F (2017) Organization in response to massive afflux of war victims in civilian practice. Experimental feedback from the November 2015 Paris terrorist attacks. J Visc Surg 153:S3-S7

16 David JS, Bouzat P, Raux M (2019) Evolution and organization of trauma systems. Anaesth Crit Care Pain Med 38: 161-167

17 Sockeel P, De la Villeon B, Goudard Y, Goin G, Monchal T, Pauleau G (2017) Medical and surgical triage.J Visc Surg, 154 (Suppl 1):S13-S17 
19 Baker SP, O'Neill B, Haddon W, Long WB (1974) The injury severity score: a method for describing patients with multiple injuries and evaluating emergency care. $\mathrm{J}$ Trauma14:187-196

20 Boyd CR, Tolson MA, Copes WS (1987) Evaluating trauma care: the TRISS method. Trauma Score and the Injury Severity Score. J Trauma 27:370-378

21 Riou B, Landais P, Vivien B, Stell P, Labbene I, Carli P (2001) The distribution of the probability of survival is a strategic issue in randomized trial in trauma. Anesthesiology 95:56-63

22 Gutierrez de Ceballos JP, Fuentes FTG, Diaz DP, Sanchez MS, Llorente CM, Guerrero Sanz JE (2005) Casualties treated at the closest hospital in the Madrid, March 11, terrorist bombings. Crit Care Med 33:S107-S112

23 Gaarder C, Jorgensen J, Kolstadbraaten KM, Saksen KS, Skattum J, Rimstad R, Gundem T, Holtan A, Walloe A, Pillgram-Larsen J, Naess PA (2012) The twin terrorist attacks in Norway on July 22, 2011: the trauma center response. J Trauma Acute Care Surg 73:269275

24 Turégano-Fuentes F, Pérez-Díaz D, Sanz-Sánchez M, Ortiz Alonso J (2008) Overall Asessment of the Response to Terrorist Bombings in Trains, Madrid, 11 March 2004. Eur J Trauma Emerg Surg 34:433-441

25 Aylwin CJ, Konig TC, Brennan NW, Shirley PJ, Davies G, Walsh MS, Brohi K (2006) Reduction in critical mortality in urban mass casualty incidents: analysis of triage, surge, and resource use after the London bombings on July 7, 2005. Lancet 368:2219-2225

26 Tourtier JP, Palmier B, Tazarourte K, Raux M, Meaudre E, Ausset S, Sailliol A, Vivien B, Domanski L, Carli P (2013) The concept of damage control: extending the paradigm in the prehospital setting. Ann Fr Anesth Reanim 32:520-526 
27 Gauss T, Balandraud P, Frandon J, Abba J, Ageron FX, Albaladejo P, Arvieux C, Barbois S, Bijok B, Bobbia X, Charbit J, Cook F, David JS, Maurice GS, Duranteau J, Garrigue D, Gay E, Geeraerts T, Ghelfi J, Hamada S, Harrois A, Kobeiter H, Leone M, Levrat A, Mirek S, Nadji A, Paugam-Burtz C, Payen JF, Perbet S, Pirracchio R, Plenier I, Pottecher J, Rigal S, Riou B, Savary D, Secheresse T, Tazarourte K, Thony F, Tonetti J, Tresallet C, Wey PF, Picard J, Bouzat P (2019) Strategic proposal for a national trauma system in France. Anaesth Crit Care Pain Med 38:121-130

28 Sollid SJ, Rimstad R, Rehn M, Nakstad AR, Tomlinson AE, Strand T, Hemdal HJ, Nilsen JE, Sandberg M (2012) Oslo government district bombing and Utøya island shooting July 22, 2011: the immediate prehospital emergency medical service response. Scand J Trauma Resusc Emerg Med 20:3

29 Klassen AB, Marshall M, Dai M, Mann NC, Sztajnkrycer MD (2018) Emergency medical services response to mass shooting and active shooter incidents, United States, 2014-2015. Prehosp Emerg Care 34:1-8

30 Shapira SC, Adatto-Levi R, Avitzour M, Rivkind AI, Gertsenshtein I, Mintz Y (2006) Mortality in terrorist attacks: A unique modal of temporal death distribution. World J Surg 30:2071-2077

31 Gates JD, Arabian S, Biddinger P, Blansfield J, Burke P, Chung S, Fischer J, Friedman F, Gervasini A, Goralnick E, Gupta A, Larentzakis A, McMahon M, Mella J, Michaud Y, Mooney D, Rabinovici R, SweetD, Ulrich A, Velmahos G, Weber C, Yaffe MB(2014) The initial response to the Boston marathon bombing: Lessons learned to prepare for the next disaster. Ann Surg 260:960-966

32 Leibovici D, Gofrit ON, Heruti RJ, Shapira SC, Shemer J, Stein M (1997) Interhospital patient transfer: a quality improvement indicator for prehospital triage in mass casualties. Am J Emerg Med 15:341-344 
33 Yeguiayan J-M, Yap A, Freysz M, Garrigue D, Jacquot C, Martin C, Binquet C, Riou B, Bonithon-Kopp C (2012) Impact of whole-body computed tomography on mortality and surgical management of severe blunt trauma. Crit Care 16:R101

34 Brook OR, Eran A, Engel A (2012) CT multiplanar reconstructions (MPR) for shrapnel injury trajectory. Emerg Radiol 19:43-51

35 Watchorn J, Miles R, Moore N (2013). The role of CT angiography in military trauma. Clin Radiol 68:39-46

36 Shamir MY, Weiss YG, Willner D,Mintz Y, Bloom AI, Weiss Y, Sprung CL, Weissman C (2004) Multiple casualty terror events: the anesthesiologist's perspective. Anesth Analg 98:1746-1752

37 Hick JL, Einav S, Hanfling D, Kissoon N, Dichter JR, Devereaux AV, Christian MD (2014) Surge capacity principles: care of the critically ill and injured during pandemics and disasters: CHEST consensus statement. Chest, 146 e1S-e16S

38 Bradt DA, Aitken P (2010) Disaster medicine reporting: The need for new guidelines and the CONFIDE statement. Emerg Med Austral 22:483-487 


\section{Other investigators:}

Christophe Leroy, MD (Direction de l'organisation médicale et des relations avec les universités, APHP, Paris) ;Prof Thomas Lescot, MD, PhD (Sorbonne Université, Hôpital Saint Antoine, APHP, Paris France); Arnaud Folin, MD, Florent Femy, MD (Hôpital Européen Georges Pompidou, APHP, Paris) ;Kevin Kearns, MD (Hôpital d’instruction des armées Begin, Saint Mandé) ;Prof Matthieu Legrand, MD (Hôpital Saint Louis, APHP, Paris) ;Jennifer Truchot, MD (Hôpital Lariboisière, APHP, Paris) ; Prof Philippe Montravers, MD, Prof Enrique Casalino, MD (Hôpital Bichat-Claude Bernard, APHP, Paris) ;Prof Christophe Baillard, MD, Emmanuel Bloch-Laine, MD (Hôpital Cochin, APHP, Paris);Philippe Laitselart, MD, Elodie Schaeffer, MD (Hôpital d’instruction des armées Percy, Clamart) ;Fabrice Cook, MD, Adrien Zakine, MD (Hôpital Henri Mondor, APHP, Créteil) ;Marie Clément Kouka, MD, Brigitte Hennequin, MD (Centre Hospitalier Saint Denis, Saint Denis) ;Fatima Djamouri, MD, Christophe Quesnel MD (Hôpital Tenon, APHP, Paris) ;Romain Dufau, MD, Prof Frédéric Adnet (Hôpital Avicenne, APHP, Bobigny) ;Laurence Martineau, MD, Claire Raquillet, MD (Centre hospitalier intercommunal Robert Ballanger, Aulnay sous bois) ;Christophe VincentCassy, MD, Sophie Hamada (Hôpital Kremlin Bicêtre, APHP, Kremlin Bicêtre) ;Sébastien Beaune, MD (Hôpital Ambroise Paré, APHP,Boulogne Billancourt) ;Leila Lavagna, MD (Centre Hospitalier André Grégoire, Montreuil) ; Paer-Selim Abback, MD (Hôpital Beaujon, APHP, Clichy); Djamal Arkoub, MD (Groupe Hospitalier Intercommunal Raincy Montfermeil, Montfermeil); Catherine Le Gall, MD (Centre Hospitalier d'Argenteuil, Argenteuil); Catherine Philipoteau, MD (Centre hospitalier intercommunal de Créteil, Créteil) ; Olivier Ganansia, MD (Hôpital Saint Joseph, Paris) ; Marc Andronikof, MD (Hôpital Antoine Béclère, APHP, Clamart) ; Patrick Deschamps, MD, Centre Hospitalier René Dubos, Pontoise) ; Cécile Garot, MD (Clinique Floréal, Bagnolet); Julien Aguilar, MD (Hôpital Privé de l'ouest Parisien, Trappes) ; all in France 


\section{Figure legends}

Figure 1: Study flow chart.

Figure 2: Global cumulative frequency distribution of delay (min) from time of injury to hospital admission (A) and from time of hospital admission to first surgery (B), according to casualty mechanism of trauma (explosion injuries vs gunshot wound).

Figure 3: Delay (min) from time of hospital admission to surgery according to the type of surgery (median, interquartile, and extremes) in the study population (A) and according to the mechanism of trauma (B, explosion vs. gunshot). The size of the solid circles is proportional to the number of casualties. The $\mathrm{X}$ axis has a logarithmic scale. 


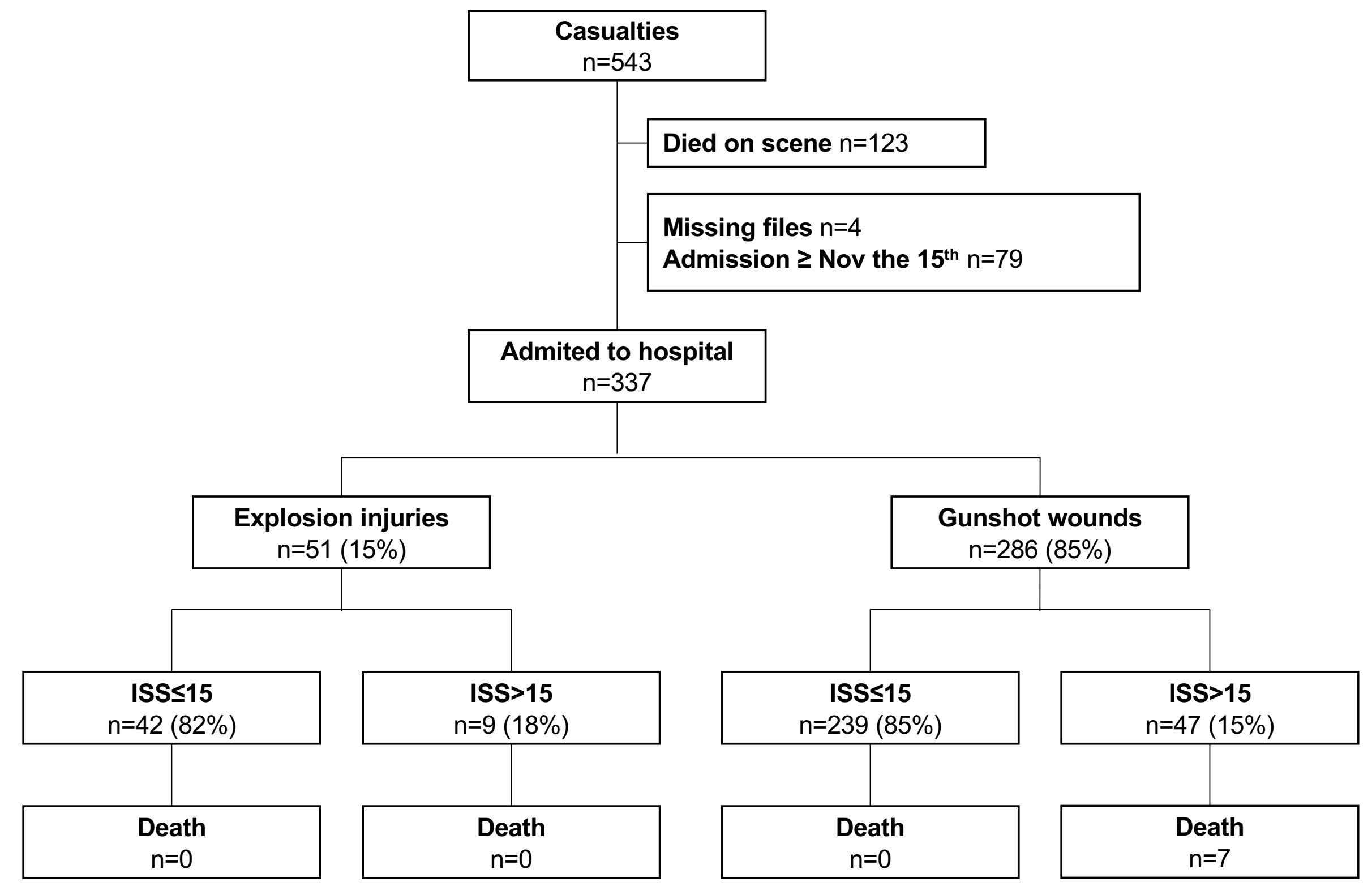


Delay from injury to hospital

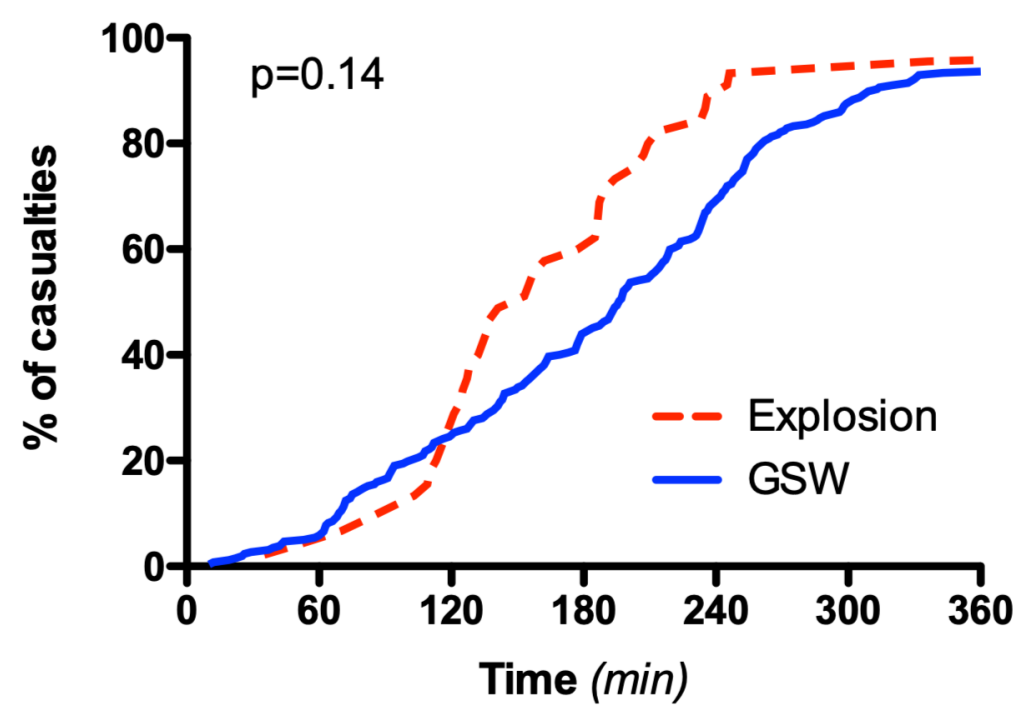

Delay from hospital arrival to first surgery

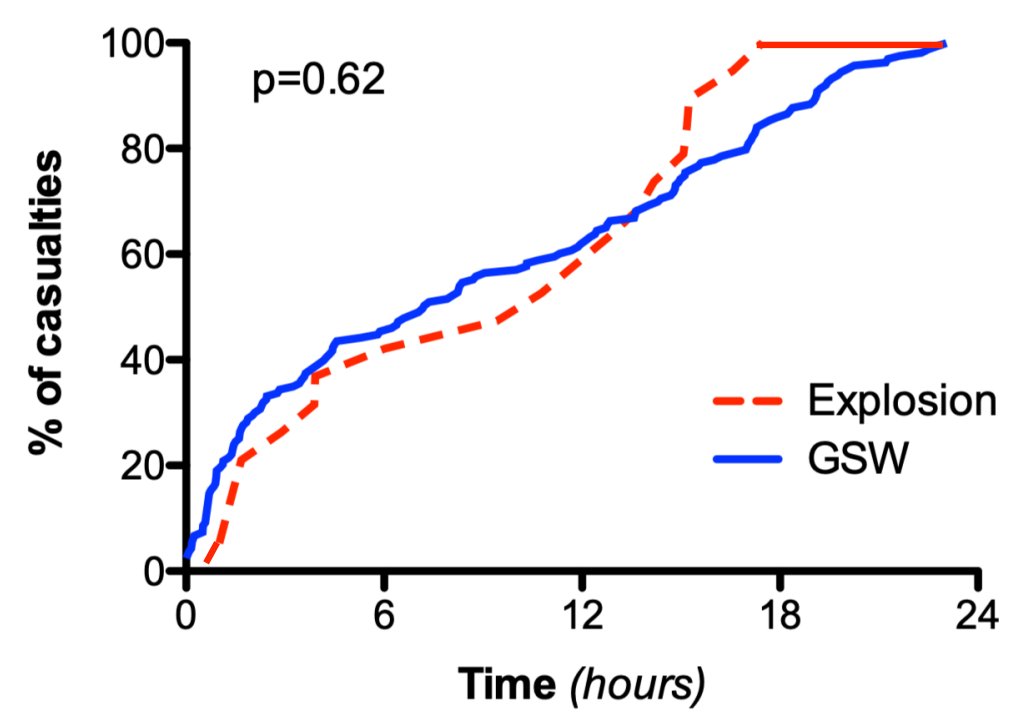

B 
Whole cohort

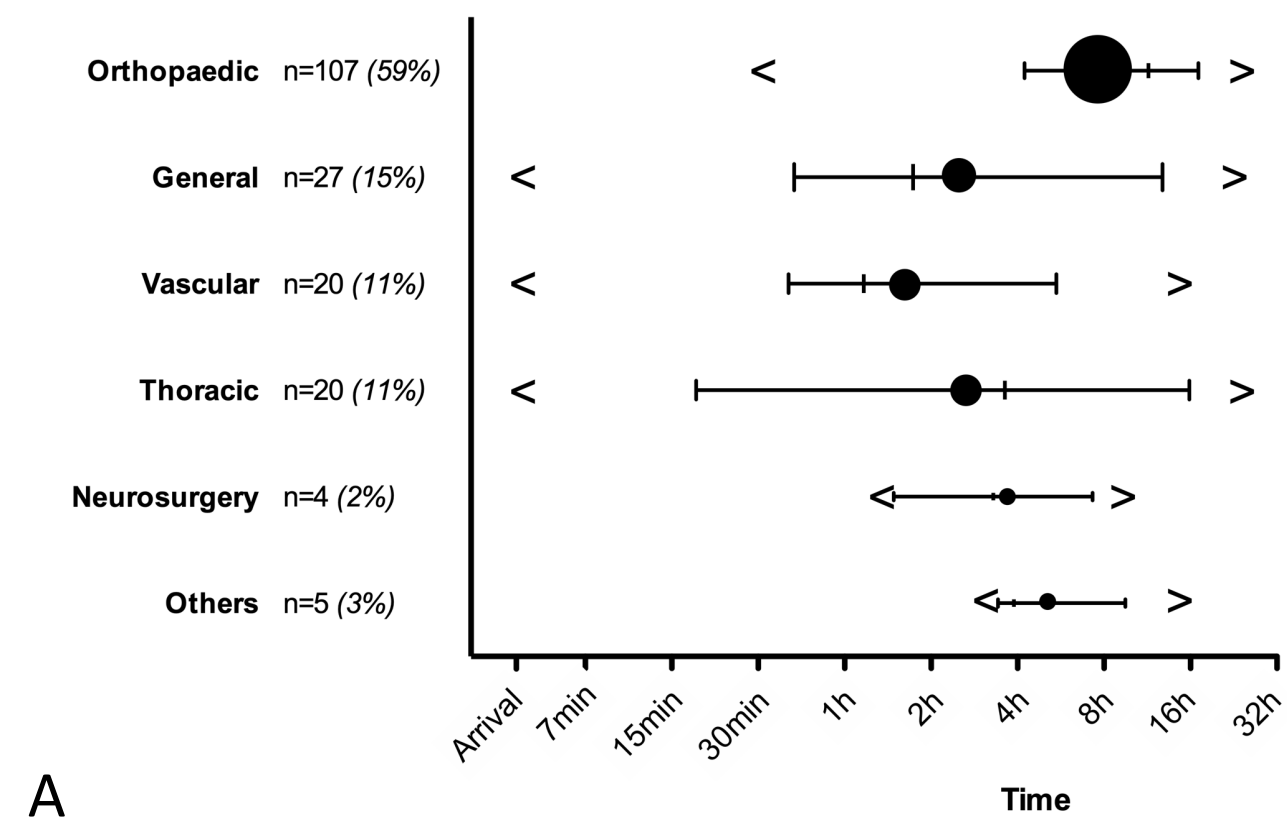

\section{Gunshot wounds and explosion}

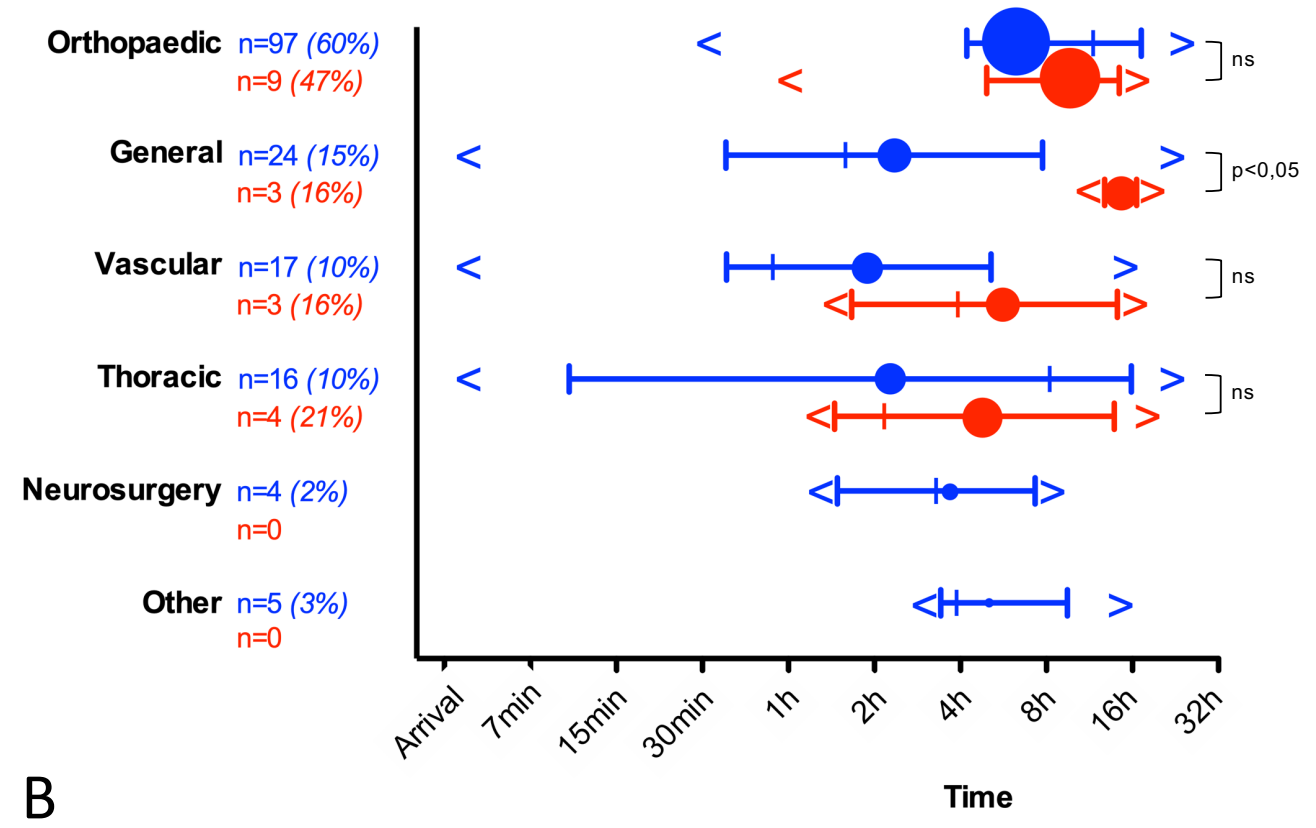

